\title{
Learner Perception on Library Services at Kandy, Matara and Anuradhapura Regional Centres of the Open University of Sri Lanka
}

\author{
P.K.M. Kaushamalika ${ }^{1}$, J.J.G. Arachchige ${ }^{2}$, W.R.W.M.A.U. Weerakoon ${ }^{3}$
}

\begin{abstract}
The study examines the usage of library and information services provided by selected regional centre libraries of the Open University of Sri Lanka. It attempts to find out the needs, expectations and usage of the library by distant learners and their perceptions about library services. The study sample $(n=350)$ was drawn from a population of 1550 students of three selected regional centre libraries of the Open University of Sri Lanka. The study found that the users are satisfied with the overall library resources, services and facilities available, but users are not really getting the full benefit of the library services and some of the services are under-utilized. The major causes or reasons for this problem are the lack of comprehensiveness of the regional library collections, insufficient space for reading area, inadequate training for users in services and the lack of computers and Internet facilities in the library. Based on these findings, it is recommended that the library should order multiple copies of reading material, extend the lending period for a period of one month in regional centres, increase the number of computers for users and provide online access facilities. It is also recommended that a comprehensive information literacy program should be conducted to promote awareness and use of electronic information resources.
\end{abstract}

Keywords: Academic libraries, Distance learning, Library facilities, Library support services, Library usage

\footnotetext{
${ }^{1}$ Assistant Librarian, Library, Matara Regional Centre, Open University of Sri Lanka, Email: pkkau@ou.ac.lk, Dhttps://orcid.org/0000-0002-2398-5573

2 Senior Assistant Librarian, Faculty of Engineering, University of Ruhuna, Email: jagathga@lib.ruh.ac.lk

${ }^{3}$ Senior Assistant Librarian, Kandy Regional Centre, Open University of Sri Lanka, Email: auwee@ou.ac.lk
}

This work is licensed under a Creative Commons Attribution-Share A like 4.0 International License 


\section{Introduction}

Universities play a major role in the society by preparing future generations to use the acquired knowledge to fulfill their responsibilities more effectively. The libraries of these institutions serve a variety of user categories such as students, faculty, researchers, administrators and other staff with diverse information needs.

The Open University of Sri Lanka (OUSL) was established in 1980 and is one of the fifteen state-owned universities functioning under the University Act No. 16 of 1978. It is the only national university which offers study programmes through Open and Distance Learning (ODL) mode, in Sri Lanka.

Due to the nature of its teaching methodology and distributed infrastructure utility, the OUSL is able to serve the large student population scattered throughout the country. According to 2015 statistics, there are more than 35,000 students studying at the OUSL, who are being served by seven regional centers and eighteen study centers located around the country. The Central Campus and the Colombo Regional Centres are situated at Nawala. The other seven Regional Centres (RCs) are located in Anuradhapura, Badulla, Batticaloa, Jaffna, Kandy, Kurunegala and Matara.

In the recent years a strong administrative decision was taken to develop the $\mathrm{RCs}$ and as a result more facilities were provided to centers such as new buildings and staff. The number of RCs has been increased and more infrastructure development plans have been proposed. With such improvements more courses are offered at centres and concomitantly the student population at RCs have improved (Table 1). With the increasing number of students, it is obligatory that the libraries should improve their resources and services.

Distant learners of OUSL often use the library for various needs. They expect a comprehensive collection of resources, reference access facilities, staff involvement as an intermediary support and friendly and comfortable study environment within the library. Therefore, it is the library's duty to examine users' needs and make facilities available to achieve their satisfaction. 
Table 1. Student population and library user population at selected RCs

\begin{tabular}{ccccccc}
\hline Center & \multicolumn{3}{c}{ Student population } & \multicolumn{3}{c}{ No. of registered library years } \\
\cline { 2 - 7 } & Year & Year & Year & Year & Year & Year \\
& 2001 & 2009 & 2015 & 2001 & 2009 & 2015 \\
ARC & 328 & 322 & 2514 & $*$ & $*$ & 50 \\
MRC & 1046 & 1851 & 2262 & 29 & 207 & 500 \\
& & & $(22 \%)$ & & & $(141 \%)$ \\
KRC & 3024 & 4897 & 9247 & 21 & 670 & 1514 \\
& & & $(88 \%)$ & & & $(126 \%)$ \\
\hline
\end{tabular}

Note: *Lending facility was not provided; Figures within parenthesis gives the percentage increase compared to previous year; ARC - Anuradhapura Regional Centre, MRC - Matara Regional Centre, KRC - Kurunegala Regional Centre

\section{Literature Review}

The previous literature reviewed for the study is categorized under four main themes; distance learning, library usage, library services and library needs. A few selected important studies are mentioned below.

Perera (2005) reviewed fulfilling user needs is an important aspect of library management. Regular evaluation of user needs against existing services and the library collection is a necessary management technique for the continuous upgrading of the services provided by a library of any kind. The management staff of a library should be aware of the current requirements of their clients/users. User needs vary from one library to another as well as from time to time.

Gunasekara (2014) assessed the user perception on academic library services in University of Peradeniya. The findings indicated that inadequate communication between the library and its users as well as lack of knowledge and the low state of awareness of certain services and resources and inadequate training to use the services are the main factors responsible for the ways in which users perceive the services offered by the library. The study concluded that users were not receiving the full benefit of the library services and that some of the services were under-utilized. Based on the findings, it was recommended that the academic library should conduct comprehensive information skills development programmes to promote 
awareness and increase the use of library services. It was recommended that regular orientation sessions should be conducted for students to raise their awareness of the library services so that their usage will be increased. The survey further established a need for a better liaison between library and faculty staff. Therefore, it was also recommended to identify strategies to develop library faculty collaboration.

A recent study by Wanigasooriya (2017) tried to identify user perception on library staff, users' minimum and desired expectations from library staff, identify the users' difficulties encountered from the receipt of library services and determine the necessary modifications to upgrade the service quality of the university libraries in Sri Lanka. The study found that although, users were not expecting library employees' individual attention while they utilize the library for numerous purposes, users have concerns on library employees' knowledge and dependability in handling their service problems. Therefore, this study has observed that the librarians' helpfulness, understanding of users' information needs, willingness in handling their service problems were areas of less satisfaction in Sri Lankan university libraries. To overcome the above identified matters, developing library employee's training/motivation programs and recruiting employees, atleast to satisfy minimum required employees for libraries is essential.

Nkamnebe, Udem, and Nkamnebe, C.B. (2014), while assessing the frequency of the use of the library and users' satisfaction with the services and facilities provided in a Nigerian University, recommended among others that the habit of using the Library should be inculcated into students through avenues such as organizing library display, library exhibition, library orientation, and inclusion of use of library as a course in the University's curriculum so as to attract students to the Library.

According to Gulin and Ilkay (2012), the competitive environment in which university libraries operate and provide their services and resources is one of the biggest challenges to engage today's undergraduate students. There is a limited amount of high quality attention and time students which engaged with what the library offers for them. Planning and designing library awareness and information literacy programs, particularly for new students, 
has presented itself as an on-going challenge for librarians worldwide in recent times.

Student support services including library services are regarded very important in distance education institutes. Therefore, many distance education institutes are concerned about the strengths and weaknesses of their support services. However, the numbers of studies carried out at OUSL in relation to the facilities at regional libraries (which are one of the major support services for distance learners) are very limited.

One of the earliest studies in 1999 by Gunasekara et al., with a sample of 106 students from the Kandy and Matara centres have identified the reasons for using/not using the library. The reasons for using the library were identified as to refer material connected to the study programme, to refer past question papers and gain extra knowledge. Half of the respondents have said that necessary materials were not available at their centre libraries. A majority of the students said that library visits were irregular and driven by specific needs. This study had suggested that facilities at regional centre libraries should be improved.

Gunasekara (2009a) investigated the usage of the borrowing facility by the distance learners of the Kandy and Matara regional centres with a sample of 407 students. The study revealed the reasons for obtaining/not obtaining library membership at their regional centre libraries, the problems faced by the learners in using the book borrowing facility and measures to promote these facilities by the regional centre libraries. Further, the study investigated the information seeking behavior of distance learners who registered at the two regional centres.

This study revealed that the majority of distance learners at both centres do not use the library facilities as anticipated by the university. According to 28 $\%$ and $37 \%$ of learners in KRC and MRC respectively, non-availability of resources at centre libraries was the most prominent variable for not obtaining the library membership. The study suggests that allocation of adequate financial resources for centre libraries to order multiple copies of books, journals is crucial in order to improve the services at the centre 
libraries. Gunasekara (2009b) further reports that as the library of the country's leading distance education institute, the OUSL library has to face a number of specific challenges related to catering to the distance learners. It is certainly possible to develop library services with the available financial support given by the Distance Education Modernisation Project to ensure necessary information for all students. Above study was used as a guide for the current research in selecting proper methodologies and conducting the research in an effective manner.

With the increase of studentship in large numbers for different programmes in regional centres, information needs of the users also need to be looked into. However, no in-depth study has been conducted in the regional centers to analyze the educational needs and academic needs of both the staff and the students. Therefore, a proper analysis to form an appropriate acquisition policy and to plan an effective library services policy is needed for the OUSL library system.

\section{Research Objectives}

The aim of this study was to examine the current status of selected RC libraries of OUSL with regard to user satisfaction and propose development requirements for satisfying the users' needs and expectations in the future. Based on the above aim, the study attempted to:

i. Identify the user objectives (needs) of visiting the library

ii. Identify how far their needs are fulfilled

iii. Identify the barriers in using the library

iv. Identify the further requirements of users

\section{Methodology}

Based on the survey method, a structured questionnaire was used to collect data from the students attached to three regional centre libraries: Kandy, Matara and Anuradhapura of the Open University of Sri Lanka in 2015. All these three regional centres of OUSL have established libraries with basic required services. Although there are $7 \mathrm{RCs}$ and 25 study points of OUSL, above three RCs were selected considering their homogeneity of services and similarity of administration and facilities. 
Registered active library student members belonging to the academic years; level 3, 4 and 5 in three selected RC libraries of OUSL were the population of this study. Thus the total population size was 1550 under this study. As the population was too large for the study, a sample of 350 respondents including level 3, 4 and 5 was randomly selected using the non-proportionate quota sampling technique. Table 2 describes the total population and sample sizes selected from each RC.

Table 2. Population and the sample size of each RC library

\begin{tabular}{lll}
\hline Regional Centre & $\begin{array}{l}\text { Population } \\
\text { (Active } \\
\text { members) }\end{array}$ & Sample \\
& 50 & 50 \\
\hline Anuradhapura Regional Centre Library & 500 & 100 \\
Matara Regional Centre Library & 1000 & 200 \\
Kandy Regional Centre Library & 1550 & 350 \\
Total & \\
\hline
\end{tabular}

As mentioned earlier, a questionnaire was the main research instrument selected to gather data and the other was focus group interviews. The user's questionnaire was divided into five main sections. Section "A" was expected to obtain demographic information and section " $\mathrm{B}$ " was for the information related to library usage. Section "C" was used to collect data related to the satisfaction levels of library factors. Section " $D$ " was aimed to find out barriers in using the library. Final section was "E" that obtained comments and suggestions. Three hundred and fifty questionnaires were distributed among the students registered in respective RC libraries. Secondly, Assistant Librarians in charge of the three regional centres of OUSL were interviewed to gather information regarding available library sources and services provided. Collected data were analyzed and tables and charts were used to present results.

\section{Data Analysis and Results}

The response rate was very high in all Regional Centers (MRC 100\%, ARC $100 \%$ and KRC $89 \%$ ). The total response rate was $96 \%$ and therefore the data collection was very successful in the study. Table 3 describes the response rate to the questionnaire. 
Table 3. Number of questionnaire distributed and the response rate

\begin{tabular}{lcccc}
\hline Centre & $\begin{array}{c}\text { Number of } \\
\text { questionnaires } \\
\text { distributed }\end{array}$ & $\begin{array}{c}\text { Number of } \\
\text { questionnaires } \\
\text { returned }\end{array}$ & $\begin{array}{c}\text { Response } \\
\text { rate at RC } \\
\text { level (\%) }\end{array}$ & $\begin{array}{c}\text { Total } \\
\text { response rate } \\
(\%)\end{array}$ \\
\hline ARC & 50 & 50 & 100 & 14.3 \\
MRC & 100 & 100 & 100 & 28.6 \\
KRC & 200 & 178 & 89 & 57.1 \\
Total & 350 & 328 & 96 & 100 \\
\hline
\end{tabular}

The results from the three centers were analyzed separately for the purpose of the study and presented in the findings section. Table 4 and 5 show the availability of information resources, services and facilities at the selected center libraries at the time of the study.

Table 4. Availability of information resources in the selected RC libraries

\begin{tabular}{lccc}
\hline \multicolumn{1}{c}{ Information Resources } & ARC & MRC & KRC \\
\hline Text books & 3500 & 8000 & 10000 \\
Course materials & 500 & 5000 & 7000 \\
Past question papers (PQP) & 300 & 1233 & 1100 \\
CD/DVD & 176 & 300 & 470 \\
Total & 4476 & 14533 & 18570 \\
As a \% of Main Library & 4.62 & 15.0 & 19.1 \\
$\begin{array}{l}\text { collection } \\
\text { Approx. number of resources }\end{array}$ & 89.5 & 29.1 & 12.3 \\
per registered user & & & \\
\hline
\end{tabular}

According to Table 4, the amount of the collection of text books is different in the three selected RC-libraries.

All the three RC libraries provide lending facility, reference service, audiovideo facility, inter library loan, photocopy service, inquiry services, and library orientation programmes. 
Table 5. Services and facilities in RC libraries

\begin{tabular}{|c|c|c|c|}
\hline \multirow{2}{*}{$\begin{array}{l}\text { Services and Facilities } \\
\text { Lending Facility }\end{array}$} & ARC & MRC & KRC \\
\hline & & & \\
\hline Reference Service & & & \\
\hline Internet Facility & & & \\
\hline Audio-video Facility & & & \\
\hline Inter Library Loan & & & \\
\hline Photocopy Service & & & \\
\hline Inquiry Services & & & \\
\hline Library Orientation Programme & & & \\
\hline
\end{tabular}

\section{$\square$ Available $\quad \square$ Not available}

Information behavior of users shows differences according to their socioeconomic characteristics such as age, sex, occupation, etc. Therefore demographic features can influence the information behavior of users. Therefore, demographic information of users in the three RCs were collected and assessed separately in the study. The overall results of the three centers show that the majority of respondents belonged to the age category below 25 years $(50.9 \%)$. A percentage of $43.6 \%$ belonged to the age category of $26-$ 36. Only $5.5 \%$ of users were above 37 years (Table 6). Gender analysis of the users shows that the majority are females (63.7\%) and unmarried students (79\%).

Employment status of users can be highly influential on the user behavior and information needs. The results show that the percentages of employed users (51\%) are slightly higher than un-employed users (49\%). Most of the employed users are government employees $(29 \%)$ followed by private $(13 \%)$ and self-employees (8\%) (Table 6).

Differences from the above general conclusions were observed in some instances. For example, a majority of users in MRC and ARC were found to be between the 26-36 age category. Further, more students at ARC were found to be self-employed. 
Table 6. Demographic characteristics of users

\begin{tabular}{lcccccccc}
\hline \multicolumn{1}{c}{\begin{tabular}{c} 
Demographic \\
\multicolumn{1}{c}{ factor }
\end{tabular}} & ARC & \multicolumn{2}{c}{ MRC } & \multicolumn{2}{c}{ KRC } & Total \\
\hline Age & $\mathrm{N}$ & $\%$ & $\mathrm{~N}$ & $\%$ & $\mathrm{~N}$ & $\%$ & $\mathrm{~N}$ & $\%$ \\
25 or below & 10 & 20 & 44 & 44 & 113 & 56.5 & 167 & 50.9 \\
$26-36$ & 30 & 60 & 52 & 52 & 61 & 30.5 & 143 & 43.6 \\
37 or above & 10 & 20 & 4 & 4 & 4 & 2 & 18 & 5.5 \\
Gender & & & & & & & & \\
Male & 15 & 30 & 36 & 36 & 68 & 38 & 119 & 36.3 \\
Female & 35 & 70 & 64 & 64 & 110 & 62 & 209 & 63.7 \\
Marital Status & & & & & & & & \\
Single & 25 & 50 & 73 & 73 & 161 & 80.5 & 259 & 79.0 \\
Married & 25 & 50 & 27 & 27 & 17 & 8.5 & 69 & 21.0 \\
Type of Employment & & & & & & & & \\
Self employed & 4 & 8 & 6 & 6 & 17 & 8.5 & 27 & 8.2 \\
Government & 36 & 72 & 37 & 37 & 23 & 11.5 & 96 & 29.3 \\
Private company & 2 & 4 & 19 & 19 & 22 & 11 & 43 & 13.1 \\
Non employed & 8 & 16 & 38 & 38 & 116 & 58 & 162 & 49.4 \\
\hline
\end{tabular}

Table 7 shows that a majority of users visit the library to refer books (59.45\%). Second major purpose of visiting the library is to search for information from the collection (50.3\%). Other purposes are to borrow or return books (48.17\%) and prepare for assignments (41.77\%). A reasonable proportion of students use the library space to read notes (39.94\%), to study with friends (37.5\%) and for relaxed reading (32\%). Only few users visit the library to surf the Internet (7\%). This is mainly because of the limitation of computer facilities in KRC and MRC and the unavailability of computer facilities in ARC.

However, it should be noted that the objective of users in different RCs show slight deviations from the general situation discussed above. For example the major objectives of students visiting the ARC library are to borrow/return books. In addition equal proportions of students visit ARC for referring periodicals as well as searching information from the collection. In MRC and $\mathrm{KRC}$ it was noted that other than referring books and searching information 
from the collection, most students visit the library to prepare for assignments (MRC) and study with friends (KRC).

Table 7. Objectives of visiting the library of RCs

\begin{tabular}{|c|c|c|c|c|c|c|c|c|}
\hline \multirow[b]{2}{*}{ Objectives } & \multicolumn{2}{|c|}{ ARC } & \multicolumn{2}{|c|}{ MRC } & \multicolumn{2}{|c|}{ KRC } & \multicolumn{2}{|c|}{ Total } \\
\hline & No & $\%$ & No & $\%$ & No & $\%$ & No & $\%$ \\
\hline Refer books & 15 & 30 & 63 & 63 & 117 & 66 & 195 & 59.45 \\
\hline $\begin{array}{l}\text { Search for information } \\
\text { from the collection }\end{array}$ & 20 & 40 & 54 & 54 & 91 & 51 & 165 & 50.30 \\
\hline $\begin{array}{l}\text { Borrow/return the } \\
\text { books }\end{array}$ & 45 & 90 & 40 & 40 & 73 & 41 & 158 & 48.17 \\
\hline Prepare assignments & 15 & 30 & 42 & 42 & 80 & 45 & 137 & 41.77 \\
\hline $\begin{array}{l}\text { Read notes (use the } \\
\text { library space) }\end{array}$ & 5 & 10 & 39 & 39 & 87 & 49 & 131 & 39.94 \\
\hline $\begin{array}{l}\text { To study with friends in } \\
\text { the library }\end{array}$ & 3 & 6 & 29 & 29 & 91 & 51 & 123 & 37.50 \\
\hline $\begin{array}{l}\text { For relaxed reading in } \\
\text { the library }\end{array}$ & 4 & 8 & 36 & 36 & 65 & 37 & 105 & 32.01 \\
\hline $\begin{array}{l}\text { Refer journals/ } \\
\text { periodicals }\end{array}$ & 20 & 40 & 12 & 12 & 29 & 16 & 61 & 18.60 \\
\hline Surf the internet & 2 & 4 & 10 & 10 & 12 & 7 & 24 & 7.32 \\
\hline
\end{tabular}

This indicates that users in each centre have unique objectives of visiting the center library thus resources, services and facilities should be provided and improved accordingly.

Fulfillment of Objectives of Visiting the Selected RC libraries

Having identified the objectives, it was investigated whether the users fulfilled their objectives of visiting the library (Table 8 ). A majority of $28 \%$ had stated that "sometimes" they were able to fulfill their objectives of visiting the library while $26 \%$ of respondents were "always satisfied". A proportion of $23 \%$ and $18 \%$ of users had fulfilled their objectives "very often" and "often" respectively. It was noted that only $3 \%$ of users have 
never fulfilled their needs. This indicates that a majority of students $(96.95 \%)$ were at least minimally satisfied by their visit to the library while $3.05 \%$ were never satisfied. More than half the students $(68.60 \%)$ were able to fulfill their needs either often, very often or always.

However, it should also be noted that the frequency of need fulfillment differs based on the centre. A majority of users in KRC (27\%) were able to fulfill their needs sometimes only, while in ARC $50 \%$ of users had fulfilled their needs very often while in MRC, $34 \%$ had always fulfilled their needs.

Table 8. Frequency of fulfillment of objectives of visiting RC libraries

\begin{tabular}{lcccccccc}
\hline & \multicolumn{2}{c}{ ARC } & \multicolumn{2}{c}{ MRC } & \multicolumn{2}{c}{ KRC } & \multicolumn{2}{c}{ Total } \\
\cline { 2 - 9 } \multicolumn{1}{c}{ Frequency } & No & $\%$ & No & $\%$ & No & $\%$ & No & $\%$ \\
\hline Always & 10 & $20 \%$ & 34 & $34 \%$ & 43 & $21.5 \%$ & 87 & 26.52 \\
Very often & 25 & $50 \%$ & 13 & $13 \%$ & 39 & $19.5 \%$ & 77 & 23.48 \\
Often & 2 & $4 \%$ & 21 & $21 \%$ & 38 & $19 \%$ & 61 & 18.60 \\
Sometimes & 7 & $14 \%$ & 31 & $31 \%$ & 55 & $27 \%$ & 93 & 28.35 \\
Never & 6 & $12 \%$ & 1 & $1 \%$ & 3 & $1.5 \%$ & 10 & 3.05 \\
\hline
\end{tabular}

Reasons for Non-Fulfillment of User Objectives

Different reasons for non-fulfilment of user objectives were identified (Table 9). A majority of respondents (36\%) had stated the insufficiency of multiple copies of books as the reason for not fulfilling their objectives. Second reason was insufficiency of the collection and the non-availability of new editions $(31 \%)$. The third reason (24\% users) was identified as the insufficiency of IT facilities. A further $19 \%$ of respondent showed that the unavailability of reference materials as the reason. A low percentage of respondents $(4 \%)$ were not satisfied with the support of the library staff. The results suggested to develop the collection of resources with multiple copies of books, new editions and increase the collection with demanded books. Especially it suggested increase IT facilities. 
Table 9. Reasons for not fulfilling the objectives of visiting the library

\begin{tabular}{lcccc}
\hline \multirow{2}{*}{\multicolumn{1}{c}{ Reasons }} & ARC & MRC & KRC & Total \\
\cline { 2 - 5 } \multicolumn{1}{c}{$\%$} & $\%$ & $\%$ & $\%$ \\
\hline Collection is not sufficient & 30 & 30 & 32 & 31 \\
Unavailability of new edition & 40 & 30 & 29 & 31 \\
Not enough multiple copies of books & 6 & 39 & 42 & 36 \\
Unavailability of reference materials & 10 & 17 & 22 & 19 \\
Staff are not supportive enough & 4 & 5 & 3 & 4 \\
IT facilities are not enough & 8 & 2 & 29 & 24 \\
\hline
\end{tabular}

\section{Barriers in Using the Library}

An open ended question was inserted in the questionnaire to encourage users to indicate the problems faced by them in using the library. Their responses were categorizing according to approximate themes and tabulated (Table 10). A majority of users (19\%) said that, relevant reading materials and resources of their subject area were not available in a sufficient amount. 15\% of users have mentioned that they have no extra time to read while $14 \%$ users say that library space was inadequate for their reading activities. For $13 \%$ of the users the distance between their residence and the center library was a barrier. Twelve percent of the respondents indicated that a two-week lending period for borrowing materials was not sufficient as they are distance learners. Furthermore, they suggested for extending the lending period to at least three weeks. Only a few of the users (5\%) denoted that it is difficult to pay the current membership fees (Rs. 500).

\section{User Desired Expectations}

Comments and suggestions of users were gathered through the questionnaires are shown in Table 11.

\section{Conclusion}

Demographic analysis revealed that the users range from young adults to mature adults above 37 years. Therefore, the library should consider adult learner characteristics and information seeking behavior when providing resources and services, introducing new services and even re-considering rules and regulations of the library. 
Table 10. Barriers of using the library of RCs

\begin{tabular}{lcccc}
\hline \multicolumn{1}{c}{ Barrier } & ARC & MRC & KRC & Total \\
\cline { 2 - 5 } & $\%$ & $\%$ & $\%$ & $\%$ \\
\hline $\begin{array}{l}\text { Unavailability of relevant subject-specific } \\
\text { reading material at centre libraries }\end{array}$ & 20 & 29 & 33.5 & 19 \\
$\begin{array}{l}\text { No time for extra reading } \\
\begin{array}{l}\text { There is inadequate space allocated in the } \\
\text { library }\end{array}\end{array}$ & 20 & 27 & 27 & 15 \\
$\begin{array}{l}\text { Distance between residence and centre } \\
\text { libraries }\end{array}$ & 30 & 20 & 24 & 14 \\
$\begin{array}{l}\text { Two-weeks lending period is not enough } \\
\text { It is difficult to pay the membership fees }\end{array}$ & 40 & 36 & 23.5 & 13 \\
\hline
\end{tabular}

Table 11. Comments and suggestions

\begin{tabular}{|c|c|c|c|c|}
\hline Comments or suggestions & $\begin{array}{c}\text { ARC } \\
(\%)\end{array}$ & $\begin{array}{c}\mathrm{MRC} \\
(\%)\end{array}$ & $\begin{array}{c}\mathrm{KRC} \\
(\%)\end{array}$ & $\begin{array}{c}\text { Total } \\
(\%)\end{array}$ \\
\hline Needs to increase the resource collection & 44 & 41 & 42 & 42 \\
\hline $\begin{array}{l}\text { Needs more computers with fast Internet } \\
\text { access and Wi-Fi }\end{array}$ & 10 & 23 & 12 & 15 \\
\hline $\begin{array}{l}\text { Library opening hours should be extended } \\
\text { during examination period. }\end{array}$ & 2 & 7 & 3 & 4 \\
\hline Needs to enhance its physical environment & 12 & 20 & 24 & 21 \\
\hline $\begin{array}{l}\text { Needs to update past question papers } \\
\text { under all subject areas }\end{array}$ & 2 & 3 & 5 & 4 \\
\hline Needs to improve the audio visual facilities & 6 & 10 & 3 & 5 \\
\hline Should extend the lending period for three weeks & 4 & 10 & 8 & 8 \\
\hline Appreciate the helpful library staff and services & 4 & 10 & 8 & 8 \\
\hline
\end{tabular}

The proportion of employed (51\%) and unemployed (49\%) users are more or less similar. Therefore the library should consider providing appropriate resources for both these groups. The employed students might concentrate on information resources directly related to their courses such as text for 
assignments, question papers etc. while the un-employed students may require reading spaces, internet facilities and study rooms. The library should also consider the provision of information related to career development and courses related to employment.

The primary reasons of visiting the library by users of the RCs were found to be to refer books and search information from the collection. Majority of users fulfill their objectives from the library Further it should be noted that the frequency of need fulfillment differs center vise. KRC has less resource per user compared to other centers. The resources per user ratio at MRC could be studied further as students have always been able to fulfil their objectives of visiting the library. Insufficiency of information resources and lack of IT facilities are considered as the major reasons for non- fulfilment of user objectives. In addition, the lack of space and staff support is also identified as reasons for user dissatisfaction.

\section{Recommendations}

The study identifies the user needs at selected RCs and barriers faced by distance learners in using the Kandy, Matara and Anuradhapura Regional Centre Libraries (KRC, MRC and ARC). Further, the study investigates the fulfillment of objectives of using the library by distance learners who registered in the selected three regional centre libraries. Considering the findings of the study, the following recommendations and suggestions can be proposed to improve the library service of RC libraries of OUSL.

Library needs to add new books, multiple copies of text books and reference resources in various subject disciplines and increase the number of journals, and add more online resources and CD/DVDs-and increase updated course materials in Sinhala, English and Tamil medium; The Library has to enhance its physical environment by providing more ventilation and enough seating capacity (Air conditioning or more fans); Library should acquire more computers with fast internet access and Wi-Fi facilities for students; Recruit more library staff and introduce new services; Develop resource collections based on the quality and quantity, making multiple copies of reading materials available, increase of media and e-resources (level-wise) in selected centre libraries keeping in mind the requirements of distance learners; Implement a reciprocal borrowing scheme for OUSL distance 
learners by the sharing of material among the Regional Centres, Main Library and other university or special libraries such as Teacher Training College Libraries; Strengthen the facilities of RC libraries with enhanced services/new services and create a conducive environment for studying in RC libraries; The selected RC libraries should provide effective signage to communicate not only the location of resources but also to provide guidance for searching for information. Colorful leaflets, pathfinders and guides containing a variety of information and instructions on how to access information both manually and electronically should be made available on a "help yourself" basis. (Orientation, at day schools); The RC libraries should organize short courses such as introduction to OPAC sessions, workshops and demonstrations on information seeking during lunch times free for all members of the University. They can be held throughout the academic year. This is one way of reaching and making users aware of its services; Signage such as "We are here to help you"; "Please feel free to interrupt" may prove helpful with an established Information/Reference Desk; Train the existing staff to develop professional skills, communication skills and soft skills like personal relationship and customer care and Awareness programmes should be organized by the library to attract the users' attention and rouse their interest in the services offered. "Library Week" or "Library Open Day" might be an effective way of getting closer to users and identifying users' needs.

\section{References}

Gulcin, C. \& Ilkay, H. (2012). Student engagement and library use: An examination of attitudes towards use of libraries and information amongst undergraduate students at a Turkish University Library. Proceedings of the IATUL Conferences. 22. Retrieved from http://docs.lib.purdue.edu/iatul/2012/papers/22

Gunasekara, C. (2014). User perception towards academics library services: a case study at University of Peradeniya, Sri Lanka. Paper presented at University. International Research Sessions, University of Peradeniya, Sri Lanka, Peradeniya. 
Gunasekara, D. (2009a). A study of the current status of non-utilization of the book borrowing facility at the Kandy and Matara Regional Centre of the OUSL; OUSL Journal, 5, 60-75

Gunasekare, D. (2009b) Distance learning support: Role of the central library of the OUSL ensuring information dissemination for the remote learners. Retrieved from http://digital.lib.ou.ac.lk/docs/handle/701300122/335

Gunasekara K.A.R.D, Lekamge G.D., Ranawake Gaya and Jayananda R. (1999) Student satisfaction with OUSL support services. OUSL Journal. $2,80-93$

Nkamnebe, E. C., Udem, O. K. \& Nkamnebe, C. B. (2014). Evaluation of the use of university library resources and services by the students of Paul University, AWKA, Anambra State Nigeria. Library Philosophy and Practice (e-journal). Paper 1147. Retrieved from http://digitalcommons.unl.edu/libphilprac/1147

Perera, P.A.S.H. (2005). A Study on the pattern of usage of library facilities at the Medical Library, University of Peradeniya. Journal of the University Librarians Association of Sri Lanka. 9, 41-61

Rae, M. (1989). Successful distance learners: Some New Zealand correspondence school strategies. In A. Tait (Ed.), Proceedings of Interaction and Independence: Student Support in Distance Education and Open Learning, Cambridge: Downing College, England

Wanigasooriya, P. (2017). User Perception on Affect of Services in University Libraries in Sri Lanka. Paper presented at International Conference on Library and Information Management, Department of Library and Information Science, Faculty of Social Sciences, University of Kelaniya, Sri Lanka, Retrieved from: http://repository.kln.ac.lk/handle/123456789/18062 